\title{
Oncophobia and attitude to the health in Russian women
}

\author{
Tamara Bebneva ${ }^{1,2 *}$, Svetlana Rogovskaya ${ }^{1,3}$ and Radzinsky VE ${ }^{1,2}$ \\ ${ }^{1}$ RAGIN (Russian Association for Genital Infections and Neoplasia), 121165, Moscow, Kutuzovsky Avenue, Russia \\ ${ }^{2}$ FGAOU VO "Peoples' Friendship University of Russia” Ministry of Education and Science 117198, Moscow, Miklukho-Maklaya street, Russia \\ ${ }^{3}$ GBOU DPO “Russian Medical Academy of Continuing Professional Education” of the Ministry of Health of Russia, 125993. Moscow, Barrikadnaya street, 2/1, \\ Russia
}

\begin{abstract}
In the Russian Federation, the growth of the oncological incidence of genital tract is registered. This requires increasing the responsibility of women for their health. The results of the All-Russian educational project "Women of different age between oncological negligence and phobia: How to prevent cancer?", which was started in 2015, are presented in the paper. The research was initiated by the Association RAGIN and is conducted with the support of MARS, DVISOR, the Association of Medical Journalists and a number of medical and public organizations.

To study the awareness of the female population and health workers regarding preventive measures and the intake of hormonal drugs, 4846 women aged 18 to 65 years who lived in 32 Russian cities filled out the special questionnaires. It is shown that not all women are reasonable about their health: a behavioral reaction in almost half of the respondents varies from negligence to phobia, including the attitude toward taking hormonal drugs. This may be the reason for refusing to visit screening examinations and late seeking medical help.
\end{abstract}

\section{Actuality}

The incidence of cancer in Russia has no tendency to decrease for most localizations $[1,2,3]$. The cancer of the reproductive organs (breast, body and cervix) of women occupies a leading position in the list of oncological diseases - $38.9 \%$, and neglect in the Russian Federation diagnostics in the III-IV stages - is very high, which involves expensive treatment, increased health care costs and a significant decrease in the quality of life of patients [1].

Based on the questionnaire, an educational project has been developed, including interactive lectures "Oncopatrol" and master classes. The project has already covered 34 cities in Russia, Azerbaijan and Kazakhstan. The active participants in the seminars are the organizers of public health care, researchers, teachers of departments, doctors, cytologists, laboratory diagnostics doctors, patients, teachers, psychologists.

The study is supported by the Russian Association for Genital Infections and Neoplasia (RAGIN), the Interdisciplinary Association of Specialists in Reproductive Medicine (MARS) by the Far Eastern Institute for the Advancement of Community Development (DVISOR), the Association of Medical Journalists (MAJ) and a number of medical and non-medical organizations in more than 30 regions of the country.

\section{Purpose of the study}

Increasing the effectiveness of prevention and early diagnosis of malignant neoplasms of the female reproductive health. Development of information and educational project for doctors and patients to improve reproductive health.

\section{Materials and methods}

For 18 months, a questionnaire was conducted for 4846 women aged 18 to 65 , which live in 32 cities located in all federal districts of the Russian Federation.
Sampling: stratified bivariate random sample. The obtained data represent the female population of Russia at the age of 18-65 by age groups, level of education, types of populated place of residence.

To conduct a comparative analysis, the questionnaires were divided into two groups: medical workers (physicians) and those not engaged in the medical sphere of the respondent (not physicians). The first group comprised 1524 (38.1\%) women, the II group - 2473 (61.9\%) of women. The main study parameters of the respondents of both groups were comparable.

\section{Results}

In the group of medical respondents, the position of reasonable vigilance $(77.0 \%)$ is significantly dominant in comparison with nondoctors $(49.8 \%),(\mathrm{p}<0.05)$.

The proportion of women who generally trust their doctors is high in both cohorts $(81.0 \%$ and $85.1 \%)$, including in the choice of hormone therapy and contraception $(79.3 \%$ and $74.2 \%)$, respectively.

Only $6.2 \%$ of women interviewed in the healthcare sector and $1.3 \%$ of non-medical workers expressed unequivocal positive attitude to the menopausal hormone therapy. This is consistent with all-Russian indicators and confirms the need to increase motivation for informed, competent advice on hormone therapy to increase the acceptability of hormonal therapy and contraception, improving health and improving

${ }^{*}$ Correspondence to: Tamara Bebneva, RAGIN (Russian Association for Genital Infections and Neoplasia), 121165, Moscow, Kutuzovsky Avenue, Russia, E-mail: bebn@mail.ru

Key words: Oncophobia, Russian women

Received: August 27, 2018; Accepted: September 27, 2018; Published: October 03,2018 
the quality of life of women. A high level of trust in doctors $(79.3 \%$ and $74.2 \%$ among doctors and non-doctors, respectively) was noted in the choice of hormonal treatment, despite the prevailing prejudice of doctors regarding hormonal contraceptives and preparations for menopausal hormone therapy. It was shown that there are no hormonal contraceptives for reasons of oncophobia - $28.8 \%$ of doctors, because of fear of thrombosis $-34.0 \%$, side effects $-27.2 \%$, etc.

\section{Discussion and conclusions}

Many women are not reasonable about their health: a behavioral reaction in almost half of the respondents varies from negligent to phobic, including the attitude toward taking hormonal drugs. This may be the reason for refusing to visit screening examinations if there is a possibility in the country for a free survey and late seeking medical help [4].

The obtained data made it possible to develop and present in 32 regions of Russia an educational project for patients and doctors that helps to form a competent, reasonable attitude to health and reduce the position of negligence or oncophobia. Representatives of the $\mathrm{MOH}$ of the Regions, heads of departments, heads of perinatal centers, teachers, psychologists, journalists take part in the project [5]. The implementation of the project contributes to raising awareness of the need for a healthy lifestyle and visits to screening examinations.

\section{References}

1. HELL Ed, Caprina VV, Starinskogo GV, Petrova P, Herzen A (2017) The state of oncological assistance to the population of Russia in $2016 \mathrm{M}$. MNIOI them is a branch of the NWIRTC of the Ministry of Health of Russia, pp: 236

2. Axel EM (2015) Morbidity and mortality from malignant neoplasms of the female reproductive system in Russia. Oncogynecology 1: 6-15.

3. HELL Ed, Caprina VV, Starinskogo GV, Petrova P (2014) Malignant neoplasms in Russia in 2012 (morbidity and mortality). Moscow: FGBU "MNIOI them. P.A. Herzen" of the Ministry of Health of Russiam pp: 250.

4. Rogovskaya SI, Mashovets SP, Moskvina NB, Akimkin VG (2016) All-Russian project "women of Balzac's age between oncological negligence and fobiey": the first results. Doktor Ru, pp: 6-10.

5. Rogovskaya SI, Gerasimenko M, Mashovets JV, Moskvina NB (2016) All-Russian project "Women of different ages between oncological negligence and fobiey": First results. Russian-Chinese Scientific Journal "Commonwealth" 5: 29-35.

Copyright: $\odot 2018$ Bebneva T. This is an open-access article distributed under the terms of the Creative Commons Attribution License, which permits unrestricted use, distribution, and reproduction in any medium, provided the original author and source are credited. 